\title{
Effect of Textile structure in the process parameters of thermoplastic bio-composite
}

\author{
Nawar kadi ${ }^{1 *}$, Behnaz Baghaei ${ }^{1}$ and Mikael skrifvars ${ }^{1}$ \\ ${ }^{1}$ Department of Textile Technology, Faculty of Textiles, Engineering and Business, University of Borås, 50190 Borås, \\ Sweden
}

\begin{abstract}
Thermoplastic bio-composite have a higher potential of use based on the sustainability benefits. Natural fibres today are a popular choice for applications in biocomposite manufacturing. Hybrid yarns are a satisfactory solution to improve the fabrication of composites containing a thermoplastic matrix and plant-based fibres. Nevertheless, it is still difficult to produce bio-composites with superior mechanical properties, due to problematic impregnation and consolidation results during the production process. This paper investigates the processing parameters for the compression moulding of two different hemp/PLA textiles structure bio-composites (warp knitting and weaving structure). Finite element simulations are used to optimise the processing parameters (pressure, temperature, and time). The results demonstrated that the textile structure has a small effect on the time of production. Main while the pressure and temperature of processing parameters depend only on the type of matrix and the thickness of biocomposite has a big impact on the time of production.
\end{abstract}

\section{Introduction}

The development of "green" materials for industrial applications is one of the most highly researched topics around the globe [1].

(La Mantia F.P. and Morreale M.) mentioned that the environmental impact can be reduced in significant way if we are using Fully biodegradable composites were matrix and reinforcement are made up of biodegradable materials.

Thermoplastic bio-composites started to be demand for various industrial applications (Thakur V.K., Thakur M.K. and Gupta R.K.). This is due to several specific advantageous characteristics that can be combined in these materials.

The mechanical properties of the final composite of thermoplastic composites with compression moulding product are influenced by the processing parameter, especially pressure, temperature and time (M.I.M. Kandar and H.M. Akil).

(Baghaei et al.) had obtained the processing parameter by testing method (experimental method) for the production of thermoplastic bio-composite based on hybrid yarn, where they demonstrated promising characteristics for thermoplastic bio-composited which they had obtained

The following study investigates the production and quality of bio-composites based on hybrid yarn fabrics. The parameter of production will be determined and improved by employing the finite element simulation. And the results will be compared with traditional way to produce these bio-composites. The experimental results will evaluate the suitability of composite simulations and investigate the possibility of optimization the process of eco-friendly biocomposites production.

\section{Materials and methods}

The composites were produced by compression moulding. For each composite we had used (10, 20 and 30 layers) of hybrid fabric $(19 \times 19 \mathrm{~cm})$ in a $0 / 90$-degree bidirectional lay-up. The Fabrics was put into an oven at $70{ }^{\circ} \mathrm{C}$ for 24 hours before processing.

For the reinforcement of the composites, hemp fibres were used in hybrid yarn form. Polylactic acid (PLA) fibres were used as the matrix in the hybrid yarns.

Two types of fabrics had used (warp knitting and weaving fabrics), the two fabrics contain 40 wt. \% reinforcement fibres (hemp) and $60 \mathrm{wt}$ \% PLA and mean surface weight of $261 \mathrm{~g} / \mathrm{m} 2$.

The finite element simulation was conducted with the Comsol Multiphysics software (Version 5.3a). The 3D geometry was assembled according to the composite lay-ups used in the experimental part (Fig.1). A block with a height of 15, 30 and $45 \mathrm{~mm}$, was built, which represents the thickness of the uncompressed composite lay-up, 
containing 10, 20, and 30 layers of fabric respectively. The applied modules are Solid Mechanics and Heat Transfer in Solids.

For the fabrication of thermoplastic composite, the three main parameters of the process are: pressures, temperature and the processing time need to be determined.

The temperature should be sufficiently high to decrease the viscosity of the molten thermoplastic, to ensure the good impregnation of PLA melt in the hemp. Simultaneously this temperature value should lower than $200^{\circ} \mathrm{C}$ inside the specimen because the hemp starts to be degraded at this temperature.

The pressure needs to be sufficient to press out the air out of the specimen, and shouldn't be so high, where the high pressure will push the fibre in the surface of the specimen, leading to a stress concentration.

The processing time should be as short as possible to increase the efficiency of a production process, and this time should be enough to have a uniform temperature distribution in the specimen.

Where the time of heating is becoming at $190 \mathrm{C}$ need 20 seconds with the pressure of $1 \mathrm{MPa}$ at point 450 seconds with the pressure of $0.15 \mathrm{MPa}$. This due that high pressure in the first step of process minimizes the thickness of the specimen, which will improve the heat transfer in it. But after this 20 second, the pressure application needs to be reduced, in order to not damage the composite and force the fibres towards the outside, due to the temperature dependency of the PLA's Young's modulus (Zhou et al.), and the effect of the textile structure was neglected.

Therefore, the pressure needs to be decreased during the process after the stabilization time for 20 seconds. The comparison between the new processes which depend on finite element simulation (FE Process) where the pressure decreases the process and the experimental process (EX Process) which has a constant pressure during the process are shown in the Fig. 3.

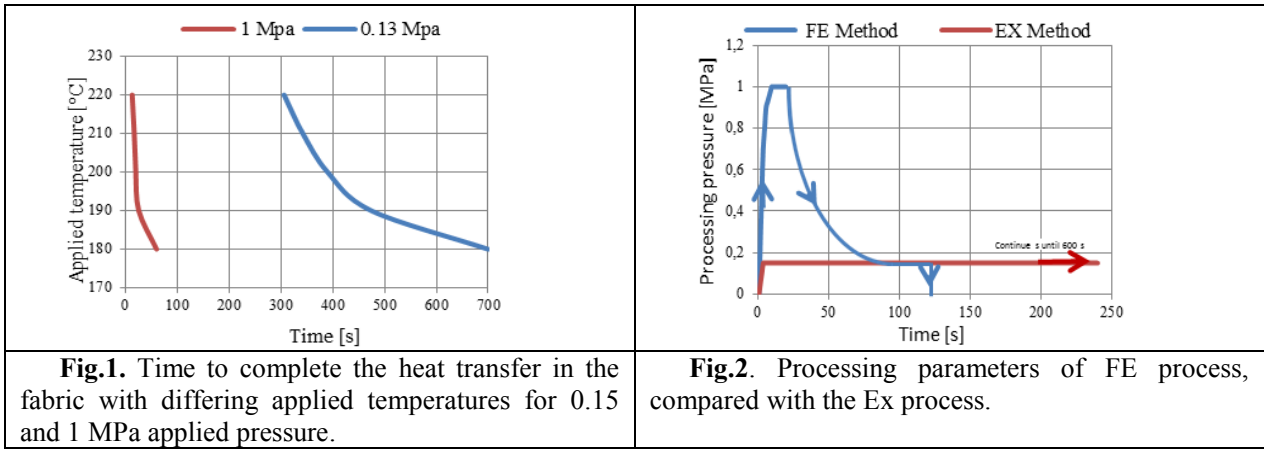

The effect of layer number demonstrated in the Fig. 4 for the two types of fabrics, where the time of process increase with a number of the layers due to the heat transfer, and the warp knitted fabric need more time compared with weaving fabric.

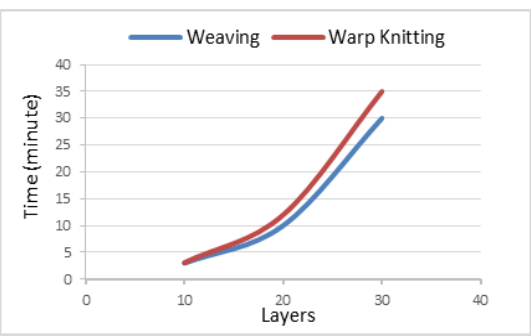

Fig. 4. Time to complete the heat transfer in the fabric for a different number of layers.

\section{RESULTS AND DISCUSSION}

The results of the tensile test are shown in Table 6. It shows an increase in tensile strength with the FE method and the weaving fabric gives the highest value. The increase in both tensile strength and modulus with the finite element method indicates an enhanced interfacial adhesion and improved overall impregnation result with the application of the FE method Fig 5 . 


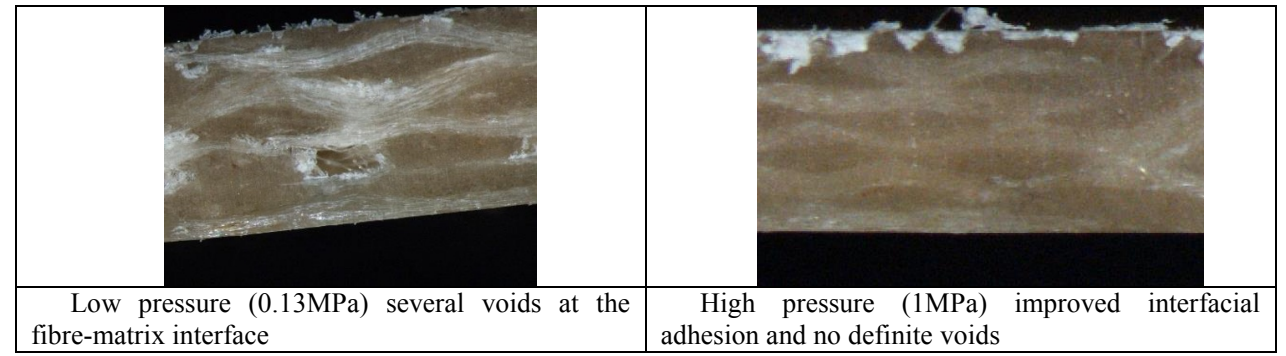

Fig.5. Microscopical picture for the different applied pressure of the biocomposite (10 layers of warp knitted fabric)

Table 2. Tensile strength and modulus of the bio-composites (10 layers)

\begin{tabular}{|l|l|l|l|l|}
\cline { 2 - 5 } \multicolumn{1}{c|}{} & \multicolumn{2}{c|}{ Weaving fabric } & \multicolumn{2}{c|}{ Knitted fabric } \\
\cline { 2 - 5 } \multicolumn{1}{c|}{} & Tensile strength & Tensile modulus & Tensile strength & Tensile modulus \\
\hline EX Process & $52.37 \mathrm{MPa}$ & $13.5 \mathrm{GPa}$ & $49.52 \mathrm{MPa}$ & $12.6 \mathrm{GPa}$ \\
\hline FE Process & $63.85 \mathrm{MPa}$ & $15.3 \mathrm{GPa}$ & $58.96 \mathrm{MPa}$ & $14.2 \mathrm{GPa}$ \\
\hline
\end{tabular}

The thermoplastic composite can be simulated by Finite element, where this finite element simulation can give important information about processing parameters for compression moulding. The effect of Young's modulus changes with the increase of the temperature must be introducing it in the simulation, in order to be able to simulate the process.

With this simulation, the time reduced in a significant way compo from the initial 10 minutes determined through experimental work, to a mere 2 minutes.

The findings from the experimental analysis suggest a trend for improvement in mechanical properties with the FE method, due to a better impregnation result.

Overall, the textile structure doesn't affect the process parameter a lot but the weaving structures give a highest tensile strength and modulus, and the thickness of biocomposite have a big impact on the time of production

\section{References}

1. G. Marsh, "Next step for automotive materials. Materials Today”, 6(4), pp. 36-43, 2003.

2. F. P. La Mantia, and M. Morreale, "Green composites: A brief review”. Composites: Part A, Vol 42, pp. 579-588, 2011.

3. V.K. Thakur, M.K. Thakur, and R.K. Gupta, "Review: Raw Natural Fiber-Based Polymer Composites", International Journal of Polymer Analysis and Characterization 19(3), pp. 256-271, 2014.

4. M.I.M. Kandar, H.M. Akil, "Application of Design of Experiment (DoE) for Parameters Optimization in Compression Moulding for Flax Reinforced Biocomposites", Procedia Chemistry 19, pp. 433-440, 2016.

5. B. Baghaei, M. Skrifvars, M. Salehi, T. Bashir, M. Rissanen, P. Nousiainen, "Novel aligned hemp fibre reinforcement for structural biocomposites: Porosity, water absorption, mechanical performances and viscoelastic behaviour", Composites Part A: Applied Science and Manufacturing vol. 61 pp. 1-12, 2014.

6. B. Baghaei, M. Skrifvars, "Characterisation of polylactic acid biocomposites made from prepregs composed of woven polylactic acid/hemp-Lyocell hybrid yarn fabrics, Composites" Part A: Applied Science and Manufacturing vol. 81, pp. 139-144, 2016.

7. B. Baghaei, M. Skrifvars, L. Berglin, "Manufacture and characterisation of thermoplastic composites made from PLA/hemp co-wrapped hybrid yarn prepregs", Composites Part A: Applied Science and Manufacturing Vol. 50 pp. 93-101, 2013.

8. B. Baghaei, M. Skrifvars, L. Berglin, "Characterization of thermoplastic natural fibre composites made from woven hybrid yarn prepregs with different weave pattern”, Composites Part A: Applied Science and Manufacturing Vol. 76 pp. 154-161, 2015.

9. C. Zhou, H. Guo, J. Li, S. Huang, H. Li, Y. Meng, et al. "Temperature dependence of poly(lactic acid) mechanical properties". RSC Advances. 6(114):113762-72, 2016. 